\title{
Experimental Evaluation of an Interleaved Boost Topology Optimized for Peak Power Tracking Control
}

\author{
Christopher D. Lute, Marcelo Godoy Simões, and \\ Danilo Iglesias Brandão \\ Electrical Engineering and Computer Science \\ Colorado School of Mines \\ Golden, USA
}

\author{
Ahmed Al Durra, and S. M. Muyeen \\ Electrical Engineering \\ The Petroleum Institute \\ Abu Dhabi, UAE
}

\begin{abstract}
This paper provides an experimental evaluation of a four phase Floating Interleaved Boost Converter for a photovoltaic power system application. This converter offers improved efficiency and voltage gain, while having lower input current ripple than other DC-DC boost converters. A dual loop, discrete, linear feedback was developed to regulate inductor currents and output capacitor voltages. Maximum Power Point Tracking capability was included. Results of all control functions were used to validate the control development, and point to areas for further improvement.
\end{abstract}

Keywords-DC-DC converter modeling, discrete control, linear feedback control, Maximum power point tracking, photovoltaic, Pulse Width Modulation

\section{INTRODUCTION}

Renewable power generation technologies, such as solar and wind, are receiving increased interest for electricity production because they are non-polluting and do not derive from finite resources. Solar photovoltaic (PV), in particular, has found numerous applications, ranging from small, standalone systems to utility-scale, grid-connected power plants [1]. At the end of 2012, cumulative installed, grid-connected PV capacity in the US reached approximately $7.4 \mathrm{GW}$. Of the nearly $316,000 \mathrm{PV}$ installations which were connected to the grid in 2012, approximately 283,000 (nearly 90\%) were residential systems [2].

PV modules produce low magnitude, Direct Current (DC) voltage, typically around 20-30 Volts (V) [3]. However, a high input voltage is necessary for efficient conversion to Alternating Current (AC) when using a DC-AC inverter. This is typically accomplished through the use of a DC-DC boost converter, which produces the high voltage necessary to drive an inverter.

The key desirable characteristics for a DC-DC converter for PV applications include: high efficiency, high voltage gain, and low input ripple. High efficiency is important for all renewable energy applications, as electricity produced by renewable sources tends to be more expensive than conventional sources. For this reason, minimizing losses is important. High voltage gain allows the PV array to use the minimum number of series connections, while still producing a high voltage DC suitable for inversion. Input ripple causes a PV module to deviate from its Maximum Power Point (MPP), resulting in lower energy yield.

The floating, interleaved boost converter (FIBC) has been proposed as a solution for fuel cell, electrical vehicle and PV applications due to its high voltage gain, high efficiency, and low input-current ripple [4]. Laboratory prototypes have been developed to demonstrate the operational principles of this converter type [4], [5]. Experimental results have also been obtained using an emulated fuel cell power source [6], [7].

This paper provides an experimental evaluation of a four phase FIBC. A discrete, dual loop controller for regulating both inductor currents and capacitor voltages will be described. MPPT capability will be integrated. Modeling and simulation results will be used to validate the design. Finally, the development of a hardware prototype will be described, and experimental results presented. Previous laboratory prototypes have been demonstrated using open loop control [4], [8]. Others have been demonstrated for fuel cell applications, using a real time dSPACE control card [6], [7], [9], or for electrical vehicles using a digital signal controller [5]. This hardware prototype will differ by being specific for PV. It will use an embedded dsPIC microcontroller with fixed point arithmetic to conduct all necessary control functions.

\section{CONVERTER OPERATION AND TOPOLOGY}

The circuit schematic for the four phase FIBC is shown in Fig 1. Although the FIBC requires a greater number of components than conventional converters, it benefits from increased efficiency and voltage gain compared to conventional converters. It also reduces the required voltage and current ratings for semiconductor devices (e.g., transistors, diodes), and the required voltage rating of the output capacitors.

These advantages have led to it being proposed as a suitable solution for fuel cell, electrical vehicles and PV power system applications. Ideal current and voltage waveforms for this converter can be found in [9].

The authors are grateful to The Petroleum Institute, Abu Dhabi, UAE for providing the funding support for this research. 


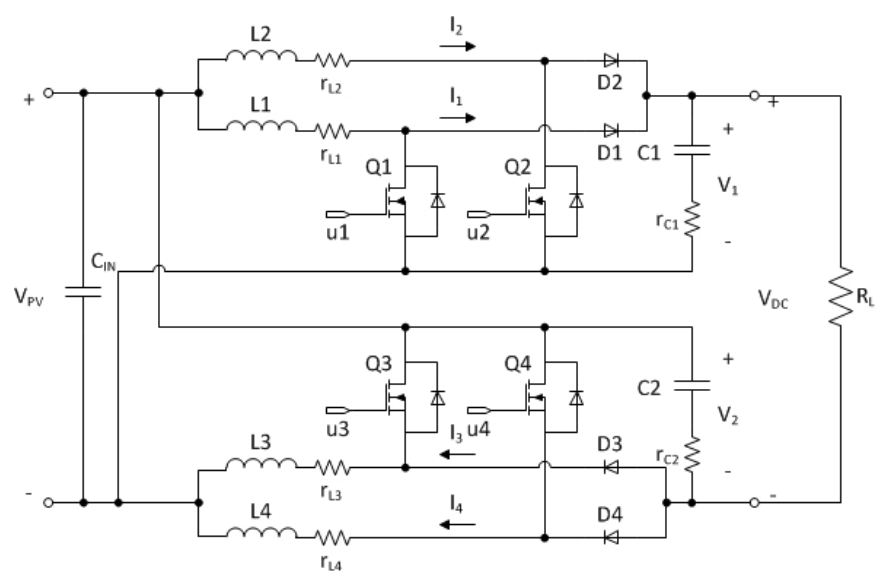

Fig 1. Circuit schematic of 4P FIBC.

\section{INTERLEAVED BOOST CONVERTER ANALYSIS}

First, it is assumed that in each switching period the average voltage across the inductors and the average current through the capacitors are null. In addition, in steady state the average current is assumed to be identical through each inductor, and the average voltage is equal across both capacitors. Then, the output/input voltage ratio (voltage gain) can be easily found by analyzing one of the passive elements that transfers energy from input to output. Choosing the inductor $\mathrm{L}_{1}$ operating in continuous conduction mode, the following equation can be defined:

$$
V_{P V} \cdot U+(1-U) \cdot\left[V_{P V}-\frac{1}{2} \cdot\left(V_{D C}+V_{P V}\right)\right]=0
$$

where $U$ is the duty cycle of the four switches.

From this, the 4P FIBC static characteristic $[\mathrm{H}(\mathrm{u})]$ can be written as:

$$
H(u)=\frac{V_{D C}}{V_{P V}}=\frac{1+U}{1-U}
$$

This reveals one of the implicit advantages of the FIBC as compared to a conventional boost converter, whose static characteristic is:

$$
H(u)=\frac{1}{1-U}
$$

The $(1+\mathrm{U})$ expression in the numerator of the static transfer function for the $4 \mathrm{P}$ FIBC allows it to produce a higher output voltage for the same duty cycle than a conventional boost converter. The state space equations and control transfer functions for this converter can be found in [10].

\section{CONTROL DESIGN}

A dual loop, discrete, linear feedback controller was developed for the four phase FIBC. A block diagram of this controller is shown in Fig. 2. This used four, independent, inner current control loops to regulate the current through each of the four inductors. An outer voltage control loop was used

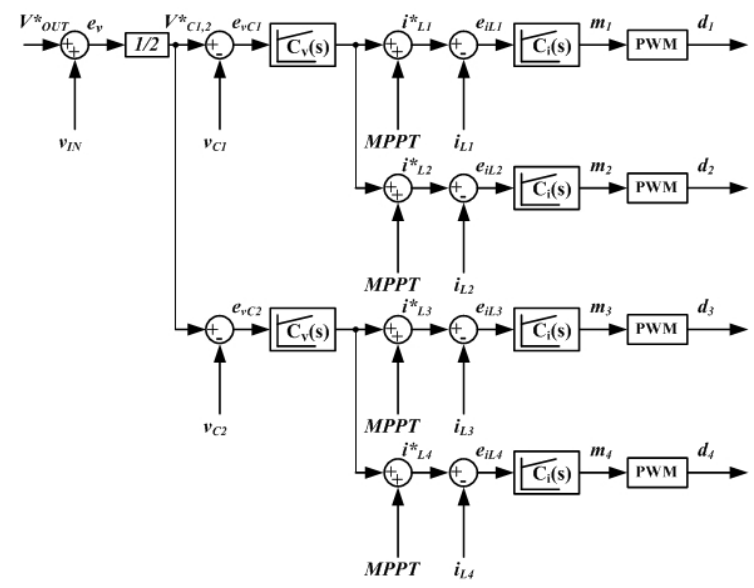

Fig. 2. Control block diagram for 4P FIBC.

to regulate the two output capacitor voltages. Regulating the two output capacitor voltages independently, rather than attempting to regulate the full DC link voltage, has been shown to yield improved performance for a PV input source under low irradiance operating conditions [10].

An additional term from the MPPT was added to the current reference originating from the outer current control loops. The outputs from the current control loops were then used as the modulation signals for four Pulse Width Modulation (PWM) controllers, which provided the $19.53 \mathrm{kHz}$ gate pulse signals for the four MOSFET switches independently.

\section{A. Current Control Loop:}

The inner current control loop was designed first, considering only the closed control loop for the current controller. The $f_{c}$ and $\mathrm{PM}$ were defined as $1.5 \mathrm{kHz}$ and $75^{\circ}$, respectively. Using classical frequency method, the controller in (4) can be designed.

$$
C_{i}(s)=\frac{(0.01 s+26)}{s}
$$

\section{B. Voltage Control Loop}

After the current controller, the voltage control loop was designed, which depended on the inner current control loop. The desirable $f_{c}$ and $\mathrm{PM}$ were designed to be $5 \mathrm{~Hz}$ and $85^{\circ}$. This low $f_{c}$ was necessary to prevent ripple in the voltage of the output capacitors from inducing steady state oscillation in the inductor current reference value. Using a low pass filter with a lower $f_{c}$ could potentially allow the bandwidth for this controller to be increased. The PI controller in (5) has been designed based on these values for $f_{c}$ and PM.

$$
C_{v}(s)=\frac{(0.04 s+7)}{s}
$$

\section{Discrete Controller}

The PI controllers were discretized using the Tustin approximation for the integration [11]. The discrete sampling of the inductor currents was synchronized to occur at the center of either the on or off switching pulse. For these 
currents, the ripple corresponded to the switching frequency, and therefore, the average value of the signal could be obtained by sampling at this time, without low pass filtering [11]. This allows for faster controller response. For low duty cycle, the sample occurred during the off pulse, and for high duty cycle it was synchronized with the center of the on pulse. In this way, the current could be sampled during the part of the period when its slope was lowest, thereby minimizing skewing error due to imprecisely synchronized sampling.

All calculations were performed using fixed point arithmetic to minimize computational time requirements. This entailed scaling the controller gain values. These were scaled by a constant $m / K_{A D C}$, where $m$ was the maximum value for the modulation index of the control loop $\left(2^{15}\right.$ in this case for 16 bit signed integers) and $K_{A D C}$ was the gain associated with the analog to digital conversion. The controller output was then scaled according to the binary counter. This was chosen to be 2,048 , corresponding to a period of $51.2 \mu$ s and, being a power of two, allowed the scaling to be accomplished using register shifting, further reducing the computational time. This reduced the switching frequency from $20 \mathrm{kHz}$ to $19.53 \mathrm{kHz}$.

\section{Maximum Power Point Tracking}

Solar PV modules have a non-linear voltage versus current relationship. For part of their operational range, PV modules are approximately current sources, while for the other portion of their range they operate as voltage sources. The result of this is that there exists one point along the voltage/current curve for which the power produced by the PV device is at its maximum. This is illustrated in Fig 3. The location of the MPP varies under varying irradiance and temperature conditions.

A number of techniques have been developed in order to operate PV systems at their MPP [12]. These techniques are known collectively as MPPT. Two different conventional MPPT techniques, the Perturb and Observe (P\&O) and the Incremental Conductance (IC) methods, were compared for the FIBC in simulation [13]. For the hardware implementation, the Constant Voltage $(\mathrm{CV})$ and IC methods were used.

One notable issue with implementing MPPT for the FIBC was in accurately determining the total input current $\left(\mathrm{I}_{\mathrm{IN}}\right)$; many MPPT strategies require $\mathrm{I}_{\mathrm{IN}}$ in order to work correctly. For the FIBC, $\mathrm{I}_{\mathrm{IN}}$ is the sum of the inductor currents (where $\mathrm{P}$ is the number of phases) minus the load current:

$$
I_{I N}=\sum_{n=1}^{P}\left(I_{L, n}\right)-I_{O U T}
$$

This is because the load (output) current is common to both the inductors on the non-floating and floating phases. Therefore, in order to obtain the input current, a fifth current sensor must be added to measure either the total input current, or the output current, so that the input current can be obtained as in (6). As the magnitude of the output current would be significantly lower, it would be more economical to measure this current.

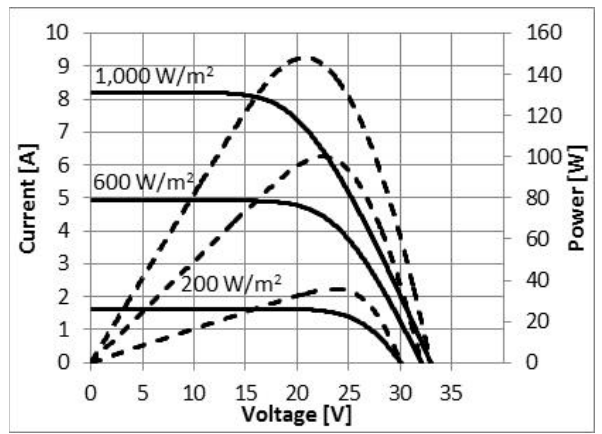

Fig 3. Generalized voltage vs. current relationship for a PV module.

\section{Simulation Results}

Matlab and Simulink software packages were used to develop and evaluate controllers. After being developed, the discrete controller was simulated in $\mathrm{C}$ code using the $\mathrm{C}$ block available in PSIM.

Two MPPT methods, the P\&O and IC techniques, were implemented using the analog and discrete controllers. Their performance was evaluated in response to step changes in solar irradiance at various temperatures.

All the simulations were conducted using PSIM with a fixed simulation time step of $0.5 \mu$ s. The input to the 4P FIBC was a mathematical model of a PV array based on 26 Kyocera KC200GT PV modules in a 2 series/13 parallel configuration. This PV module was selected because it has been well characterized and accurate models have been developed by Villalva, et al., in [14].

When used with the analog controller, the P\&O and IC techniques had virtually indistinguishable performance. Both delivered nearly identical amounts of energy to the load, and both were able to operate with very little ripple [10]. Input voltage and current ripple was calculated to be under $1 \%$ for both MPPT algorithms. Next, the P\&O and IC algorithms were evaluated using the discrete controller.

The PV power for the discrete P\&O and IC MPPT controllers in response to a step change in irradiance from $1,000 \mathrm{~W} / \mathrm{m}^{2}$ to $500 \mathrm{~W} / \mathrm{m}^{2}$ at $25^{\circ} \mathrm{C}$ is plotted in Fig. 4 . In the discrete implementation, the $\mathrm{P} \& \mathrm{O}$ technique had a more observable ripple and tended to oscillate. The IC method, in contrast, was much smoother and more stable.

While in the analog mode, input current ripple was very low $(<1 \%)$ the discrete P\&O and IC methods had input current ripple values of $6.36 \%$ and $2.90 \%$, respectively. This increased ripple resulted in lower energy capture, as the ripple caused the PV to deviate from its MPP. Overall, the discrete $\mathrm{P} \& \mathrm{O}$ delivered on average $11.84 \%$ less energy to the load. The discrete IC had much better performance, yielding on average just $1.69 \%$ lower energy capture [10]. For these reasons, the IC method was chosen to be implemented for the hardware prototype. 


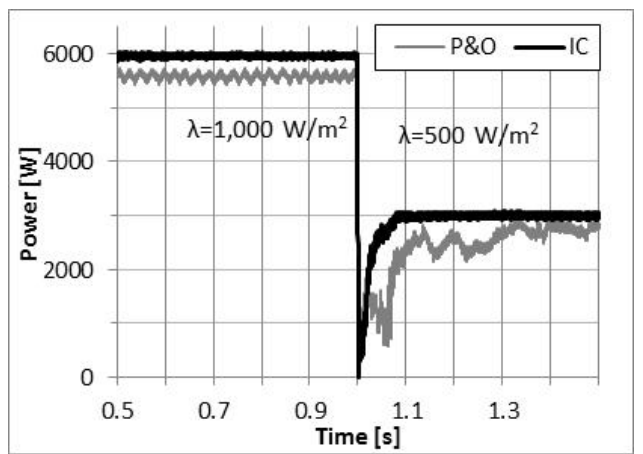

Fig. 4. PV output power for discrete $\mathrm{P} \& \mathrm{O}$ and IC MPPT methods for a step change in irradiance from 1,000 to $500 \mathrm{~W} / \mathrm{m}^{2}$ at $\mathrm{t}=1 \mathrm{~s}$

\section{EXPERIMENTAL RESULTS}

A hardware prototype was constructed that used a Microchip dsPIC33FJ256GP170A embedded microcontroller to execute control functions. These included: sampling analog feedback signals, implementing the dual-loop linear feedback control algorithms, performing MPPT, and providing the switching signals to the MOSFETs.

Four LEM LAH-25 NP Hall effect current transducers measured the inductor currents, while four LEM LV-20 P voltage transducers monitored the input, output and capacitor voltages. The outputs from the measurement devices were passed through op-amp signal conditioning circuits which scaled the outputs to match the analog measurement range of the microcontroller, and provided active low pass filtering.

An overcurrent protection circuit sensed if any inductor current exceeded $50 \mathrm{~A}$. If an overcurrent was detected, the switch pulses were disabled, a hold signal was sent to the microcontroller, and a 200 A relay was opened to isolate the source. Overvoltage protection was also included. If the output voltage exceeded $480 \mathrm{~V}$, a $2 \mathrm{k} \Omega, 100 \mathrm{~W}$ resistor was connected to the DC link by an IGBT to provide dynamic braking.

Selected device ratings and part numbers are given for key components in Table I. The inductor components were custom-manufactured, as commercially available inductors that met the desired current, inductance, and operational frequency specifications could not be found. A large inductance value $(250 \mu \mathrm{H})$ was chosen to maintain Continuous Conduction Mode (CCM) under low power conditions, such as would occur during low irradiance and/or partial shading. All control algorithms function more effectively under CCM.

One issue that had to be resolved for the hardware prototype was the issue of multiple grounds. The negative of the DC link was floating with respect to the input. Additionally, the sources of Q3 and Q4 were also floating. Isolated $48 \mathrm{~V}$ to 12 $\mathrm{V}$ DC converter modules were used to provide $12 \mathrm{~V}$ supplies for control and logic power that were referenced to the various common points. Optocouplers provided signal isolation between the microcontroller and the gate drivers. However, the isolated DC converter modules produced a great deal of electromagnetic interference, and had to be replaced with
TABLE I. Selected Component Ratings and Part Numbers

\begin{tabular}{|l|l|l|l|}
\hline Name & Description & Rating & Part number \\
\hline $\mathrm{C}_{\text {in }}$ & Input capacitor & $\begin{array}{l}330 \mu \mathrm{F} \\
350 \mathrm{~V}\end{array}$ & LNT2V331MSEC \\
\hline $\mathrm{C}_{1}, \mathrm{C}_{2}$ & $\begin{array}{l}\text { Output } \\
\text { capacitors }\end{array}$ & $\begin{array}{l}1,000 \mu \mathrm{F} \\
250 \mathrm{~V}\end{array}$ & ECOS2EP102DX \\
\hline $\mathrm{D}_{1}-\mathrm{D}_{4}$ & Power diodes & $50 \mathrm{~A}$ & RHRG560 \\
\hline $\mathrm{L}_{1}-\mathrm{L}_{4}$ & Inductors & $\begin{array}{l}250 \mu \mathrm{H} \\
40 \mathrm{~A}\end{array}$ & N/A \\
\hline $\mathrm{Q}_{1}-\mathrm{Q}_{4}$ & $\begin{array}{l}\text { MOSFET } \\
\text { switches }\end{array}$ & $\begin{array}{l}650 \mathrm{~V} \\
84 \mathrm{~A}\end{array}$ & STW88N65M5 \\
\hline
\end{tabular}

external, linear power supplies. A picture of the hardware prototype is shown in Fig. 5.

Testing was performed under low power, low voltage conditions due to limitations on source current and load dissipation capability. The experimental setup, with the external linear power supplies, is shown in Fig. 6. The input source was a $900 \mathrm{~W}$ HP 6439B DC power supply. A resistive load bank was used for the output. This setup was used to confirm basic functionality and proper control operation.

The current control loops were first validated. An external voltage source was used to provide a current reference. The current waveforms in Fig. 7 demonstrate the reduced input current ripple advantage of the FIBC. While the individual inductor currents have the characteristic triangle waveform of a conventional boost converter, the total input current is much closer to a true DC, with ripple calculated to be approximately $8.6 \%$. Fig. 8 shows the step response for a single inductor current for a step change in reference from 4 to 8 A. Fig. 9 shows the step response for all four inductor currents in response to a step change in reference from 2.5 to $4 \mathrm{~A}$.

The voltage control loop was tested using the same experimental setup, with the load impedance increased. A switched resistor allowed the load resistance to be varied between 103 and $157 \Omega$. An input voltage of $20 \mathrm{~V}$ was increased to $140 \mathrm{~V}$ at the output (a voltage gain of seven). The ability of the voltage control loop to maintain the $140 \mathrm{~V}$ output under varying load conditions was investigated. The results, shown in Fig. 10, demonstrate that the load voltage was able to be maintained, albeit with some divergence during load switching. This is the result of the low voltage controller bandwidth, as described in Section IV. The current response for the changing load is shown in Fig. 11.

As a PV input source was unavailable for testing, the MPPT control capability was tested via Thevenin's theorem for maximum power transfer, which states that for a source with a series impedance connected to load, the maximum power transfer to the load occurs when the source resistance $\left(R_{S}\right)$ is equal to the load resistance $\left(\mathrm{R}_{\mathrm{L}}\right)$. The FIBC causes the load resistance to be reflected to the input $\left(\mathrm{R}_{\mathrm{IN}}\right)$ as:

$$
R_{I N}=R_{L} \frac{(1-D)^{2}}{(1+D)^{2}}
$$

where D is duty cycle. In this case, the voltage across the load should equal half the source voltage. 


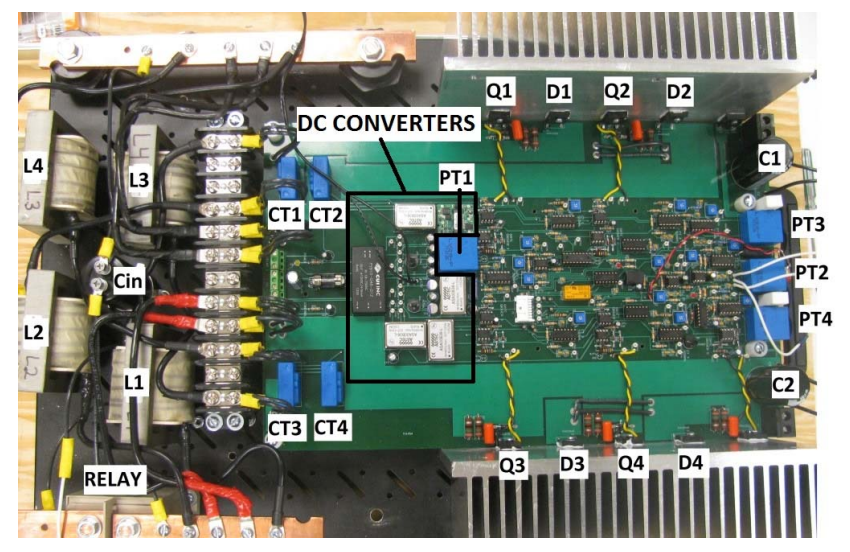

Fig. 5. 4P FIBC hardware prototype.

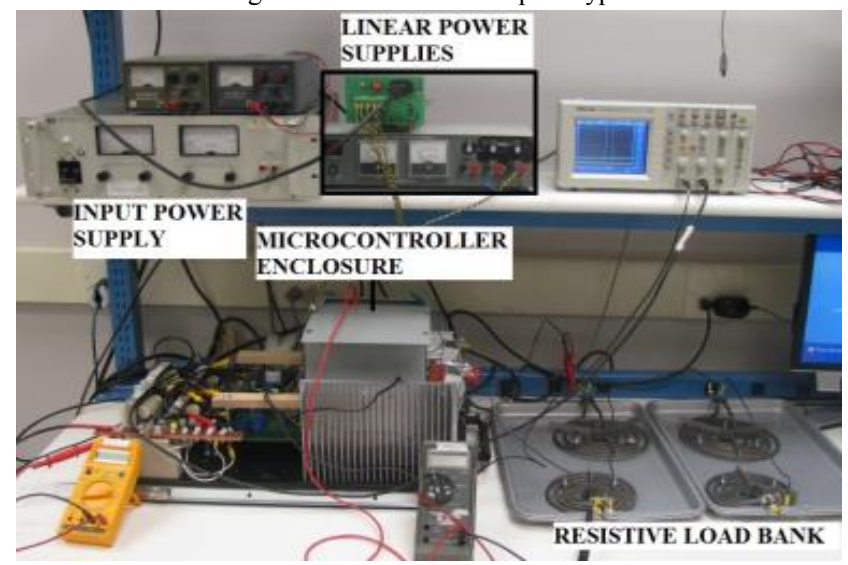

Fig. 6. Experimental test setup.

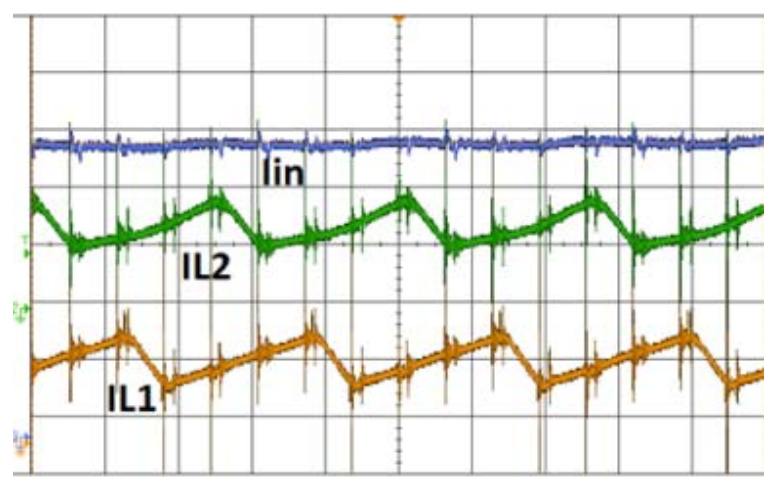

Fig. 7. Inductor currents $I_{L 1}$ and $I_{L 2}$ and input current $I_{I N}$, steady state, 3 A

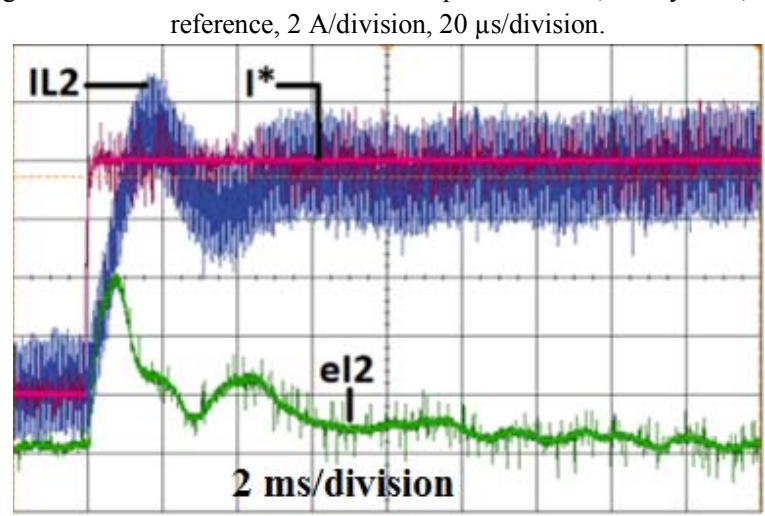

Fig. 8. Step response for inductor current $\mathrm{I}_{\mathrm{L} 2}$ and error $\left(\mathrm{e}_{\mathrm{I} 2}\right)$ for a reference ( $\left.\mathrm{I}^{*}\right)$ from 4 to $8 \mathrm{~A}$ at time $\mathrm{t}=2 \mathrm{~ms}, 1 \mathrm{~A} /$ division, $2 \mathrm{~ms} /$ division.

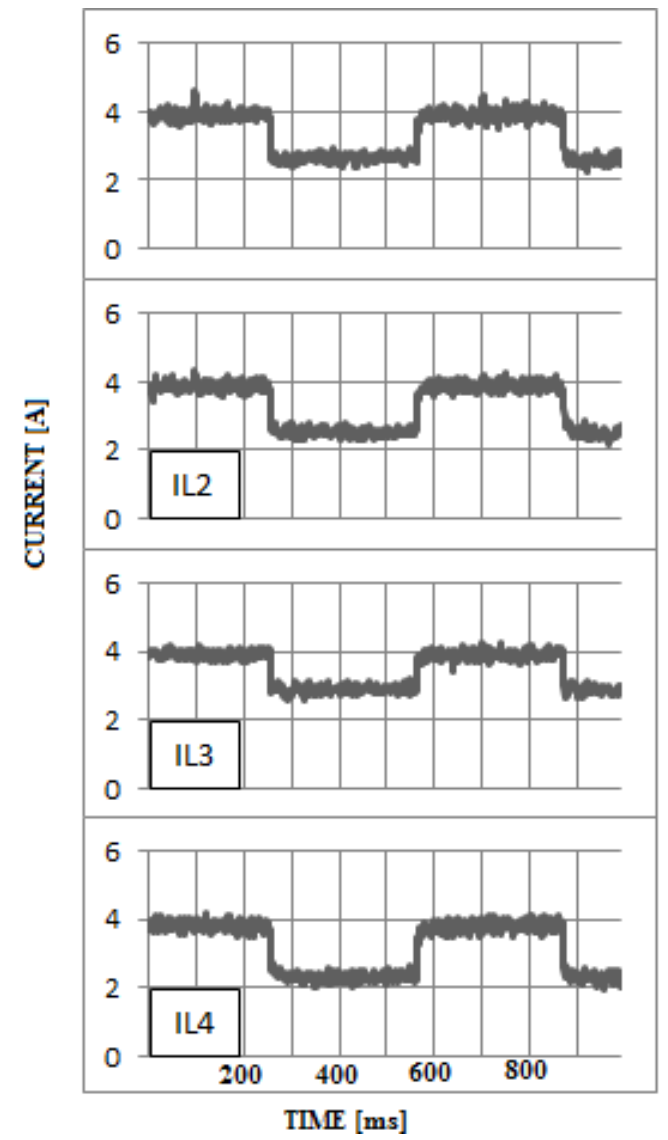

Fig. 9. Step response for four inductor currents for a reference from 2.5 to 4 A, multiple cycles, 2A/division, $100 \mathrm{~ms} /$ division.

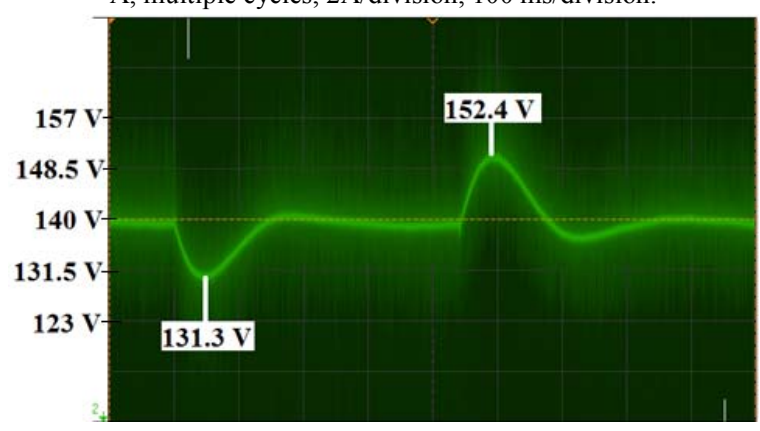

Fig. 10. Output voltage response to step change in load from $157 \Omega$ to $103 \Omega$ and back, $50 \mathrm{mV} /$ division, $50 \mathrm{~ms} /$ division.

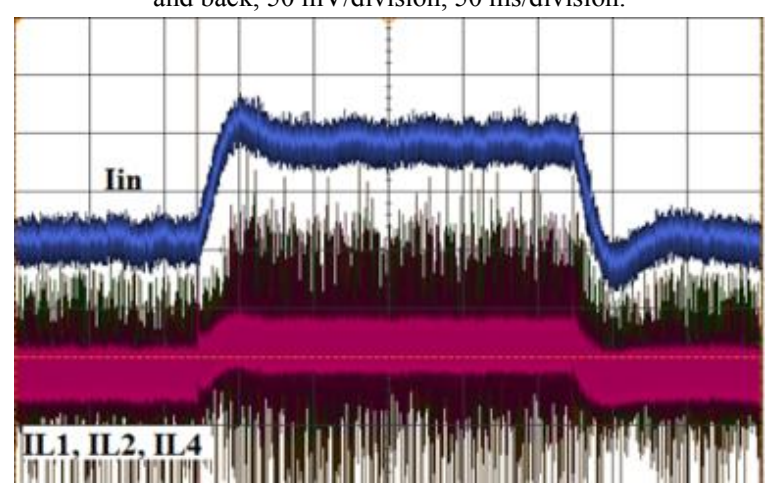

Fig. 11 Input and inductor current response for a step change in load from 157 $\Omega$ to $103 \Omega$ and back, $2 \mathrm{~A}$ /division, $100 \mathrm{~ms}$ /division. 
The steady state input power results are compared for the theoretical, CV, and IC MPPT algorithms for three different values of source resistance $(2,3$, and $4 \Omega$ ) in Table II. These results show that both algorithms were able to converge to operating points at or near the actual maximum power for each value of source resistance. The IC algorithm results were very close to the CV results for source resistance of $3 \Omega$ and $4 \Omega$, but diverged for $2 \Omega$. This is because the IC algorithm allowed the input voltage to rise for low source impedance, causing it to deviate from the maximum power point. It is anticipated that for a PV input source, which has higher input impedance, this will perform better.

Fig. 12 shows the input voltage and current response for the $\mathrm{CV}$ and IC algorithms in response to a change in source resistance from $2 \Omega$ to $3 \Omega$. Note that the $\mathrm{CV}$ algorithm holds the input voltage steady at $20 \mathrm{~V}$ (half the source voltage) and only the current varies. This matches the expected performance for this algorithm, and translates to the maximum power under these particular operating conditions. In contrast, for the IC algorithm, both input voltage and current vary in response to the changing source resistance. This resulted in lower power capture for the IC method as compared to the $\mathrm{CV}$, as plotted in Fig. 13.

The computational time requirements for the three different control loops (current, voltage, and MPPT) are listed in Table III. Computational time was measured by clearing a digital output during each control function, and measuring the time the signal was low using an oscilloscope. These demonstrate that, using the optimized, fixed point calculations, computational time for each function was minimized.

TABLE II. MPPT Input Power Comparison.

\begin{tabular}{|c|c|c|c|c|}
\hline $\begin{array}{c}\text { Source } \\
\text { Resistance }\end{array}$ & $\begin{array}{c}\text { Input Power } \\
\text { (Calculated) }\end{array}$ & $\begin{array}{c}\text { CV Input } \\
\text { Power }\end{array}$ & $\begin{array}{c}\text { IC Input } \\
\text { Power }\end{array}$ & $\begin{array}{c}\text { Percent } \\
\text { Difference }\end{array}$ \\
\hline $4 \Omega$ & $100 \mathrm{~W}$ & $99.4 \mathrm{~W}$ & $98.1 \mathrm{~W}$ & $1.3 \%$ \\
\hline $3 \Omega$ & $133.3 \mathrm{~W}$ & $132.8 \mathrm{~W}$ & $132.3 \mathrm{~W}$ & $0.4 \%$ \\
\hline $2 \Omega$ & $200 \mathrm{~W}$ & $203.8 \mathrm{~W}$ & $182.9 \mathrm{~W}$ & $10.3 \%$ \\
\hline
\end{tabular}

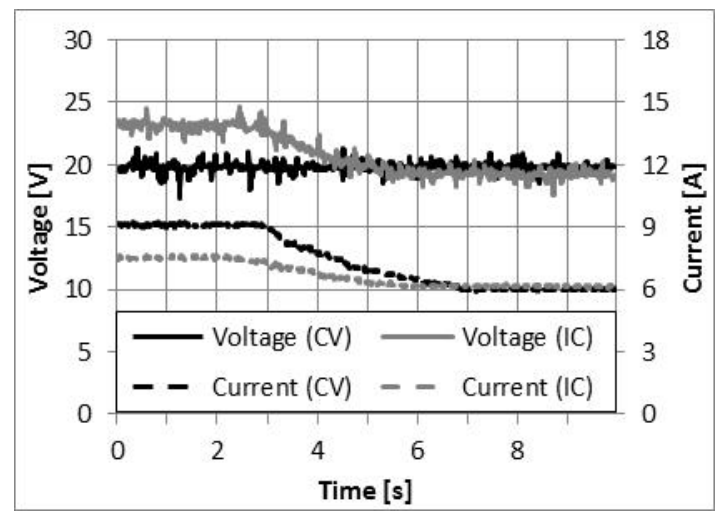

Fig. 12. Input voltage and current response for $\mathrm{CV}$ and IC MPPT algorithms in response to a change in source resistance from $2 \Omega$ to $3 \Omega$.

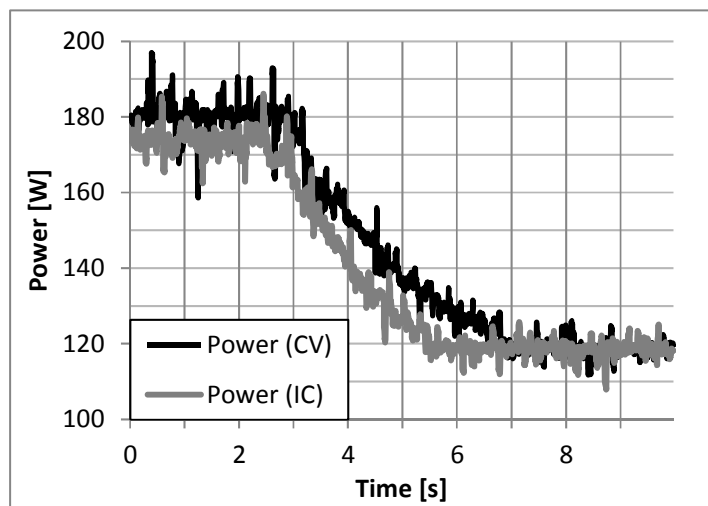

Fig. 13. Power response for CV and IC MPPT algorithms in response to a change in source resistance from $2 \Omega$ to $3 \Omega$.

TABle III. CONTRol Computation Time.

\begin{tabular}{|c|c|}
\hline Control Function & Computational Time \\
\hline Current sample, control loop & $5.6 \mu \mathrm{s}$ \\
\hline Voltage sample, control loop & $38 \mu \mathrm{s}$ \\
\hline IC MPPT & $40 \mu \mathrm{s}$ \\
\hline
\end{tabular}

\section{CONCLUSION}

This paper identified the FIBC as a promising DC-DC converter for use in PV power applications. The FIBC offers increased voltage gain and efficiency, with lower input ripple, compared to other non-isolated DC-DC converter topologies.

A dual loop PI controller regulated both the inductor currents and capacitor voltages of the four phase FIBC. Regulating the two capacitors individually was found to provide better performance under low irradiance conditions. The current and voltage controller were able to independently regulate the four inductor currents and two output capacitor voltages. Regulating these output voltages independently allowed for better convergence, particularly for a PV input under low irradiance conditions.

The MPPT capability was tested using a DC input source with a series resistance. Two different MPPT methods were compared, the CV and the IC methods. Both methods were able to converge at or near the maximum power point, but the IC method converged to a point roughly $10 \%$ below the theoretical maximum power for low source resistance. Future testing with a real or simulated PV input is required to further evaluate this controller.

The FIBC converter has numerous operational advantages that make it attractive for solar power applications. Further investigation includes testing at full power, with a real or simulated PV input source. This converter must also be evaluated as part of a complete PV power system, including a grid-connected inverter, and optionally an energy storage system.

\section{ACKNOWLEDGEMENTS}

The authors would like to gratefully acknowledge the financial support of The Petroleum Institute of Abu Dhabi for funding this research. Thanks are also due to Robert V. White, 
of Embedded Power Labs, for his support and design review for the hardware prototype. Magnetics Inc. provided the cores and bobbins for the inductors, and Badger Magnetics performed the manufacturing services. Advanced Circuits manufactured the PCB.

\section{REFERENCES}

[1] K. Bolcar, and K. Ardani, "International Energy Agency Co-operative Programme on Photovoltaic Power Systems: Task 1 Exchange and dissemination of information on PV power systems", National Survey Report of PV Power Applications in the Unites States, May 2011

[2] L. Sherwood, "U.S. Solar Market Trends 2012" Interstate Renewable Energy Council (IREC), Jul. 2013.

[3] R. Messenger and J. Ventre, Photovoltaic Systems Engineering, 2nd ed. Boca Raton, FL: CRC Press, 2004.

[4] S. Choi, et al., "Analysis, design and experimental results of a floatingoutput interleaved input boost-derived DC-DC high-gain transformerless converter," IET Power Electron., vol. 4, iss. 1, pp. 168-180, Jan. 2011.

[5] F. Garcia, et al., "Modeling an Control Design of the Interleaved Double Dual Boost Converter," IEEE Trans. Ind. Electron. vol. 60, no. 8, Aug. 2013.

[6] M. Kabalo, et al., "Experimental validation of high-voltage ratio lowinput-current-ripple converters for hybrid fuel cell supercapacitor systems," IEEE Trans. Veh. Techno., vol. 61, no. 8, Oct. 2012.

[7] M. Kabalo, et al., "Advanced hybrid dual loop control for muti-phases interleaved floating DC-DC converter for fuel cell applications," Industry Applications Society Annual Meeting (IAS), 2012 IEEE , vol., no., pp.1,8, 7-11 Oct. 2012.

[8] D. Coutellier, et al., "Experimental verification of floating-output interleaved-input DC-DC high-gain transformer-less converter topologies," Proc. IEEE PESC, 2008, pp. 562-568.

[9] M. Kabalo, et al., "Experimental evaluation of four-phase floating interleaved boost converter design and control for fuel cell applications," IET Power Electron., vol. 6, no. 2, pp. 215-226, Feb. 2013.

[10] C. Lute, et al., "Development of a Four Phase Floating Interleaved Boost Converter for Photovoltaic Systems", presented at IEEE Energy Conversion Congress and Expo, Pittsburgh, PA, 2014.

[11] S. Buso and P. Mattavelli, Digital Control in Power Electronics, Morgan \& Claypool, 2006.

[12] R. Faranda, and S. Leva, "Energy comparison of MPPT techniques for PV Systems," WSEAS Transactions on Power Systems, vol. 3, no. 6, pp. 446-455 Jun. 2008.

[13] T. Esram, and P. L. Chapman, "Comparison of Photovoltaic Array Maximum Power Point Tracking Techniques," IEEE Trans. Energy Conversion, vol. 22, no. 2, pp. 439-448, Jun. 2007.

[14] M.G. Villalva, et al., "Comprehensive Approach to Modeling and Simulation of Photovoltaic Arrays," IEEE Trans. Power Electron., vol. 24, no. 5, pp. 1198-1208, May 2009. 